\title{
Madame Riccoboni, Trois Histoires amoureuses et chavaleresques
}

Franco Piva

\section{(2) OpenEdition}

1 Journals

\section{Edizione digitale}

URL: https://journals.openedition.org/studifrancesi/26382

DOI: 10.4000/studifrancesi.26382

ISSN: 2421-5856

\section{Editore}

Rosenberg \& Sellier

\section{Edizione cartacea}

Data di pubblicazione: 1 avril 2007

Paginazione: 183-184

ISSN: 0039-2944

\section{Notizia bibliografica digitale}

Franco Piva, «Madame Riccoboni, Trois Histoires amoureuses et chavaleresques», Studi Francesi [Online], 151 (LI | I) | 2007, online dal 30 novembre 2015, consultato il 23 novembre 2021. URL: http:// journals.openedition.org/studifrancesi/26382 ; DOI: https://doi.org/10.4000/studifrancesi.26382

Questo documento è stato generato automaticamente il 23 novembre 2021.

\section{(c) $(7)$}

Studi Francesi è distribuita con Licenza Creative Commons Attribuzione - Non commerciale - Non opere derivate 4.0 Internazionale. 


\title{
Madame Riccoboni, Trois Histoires amoureuses et chavaleresques
}

\author{
Franco Piva
}

\section{NOTIZIA}

MADAME RICCOBONI, Trois Histoires amoureuses et chavaleresques. Textes établis sur l'édition originale de la Bibliothèque Universelle des Romans (1779 et 1780). Préface et notes de Pascale BologninI, Reims, Presses Universitaires de Reims, 2005 («Publications du Centre de la Recherche sur la Transmission des Modèles Littéraires et Esthétiques»), pp. 159.

1 Marie Jeanne Riccoboni era nota nel mondo delle lettere per una serie di romanzi epistolari sui quali la critica più recente ha giustamente cercato di riportare l'attenzione sia per le qualità di una scrittura che, se non raggiunge mai livelli eccezionali, presenta tuttavia una sua originalità, sia per le idee, sul matrimonio e sul rapporto uomo/donna, che essi contengono e che hanno fatto passare Mme Riccoboni, se non per una femminista ante-litteram, almeno per una donna perfettamente cosciente dei problemi che essere donna comportava nel xviII secolo. Il volumetto curato da Pascale Bolognini ce la presenta sotto una luce insolita: come collaboratrice della Bibliothèque Universelle des Romans e come adepta di quell'engouement per il Medioevo e per il genre troubadour che investì la letteratura francese negli ultimi decenni del Settecento, ed al quale La Bibliothèque Universelle des Romans contribuì non poco. Come è noto, la collezione iniziata dal marchese Paulmy d'Argenson e continuata dal conte di Tressan e da altri scrittori tra cui Bastide e Marmontel, proprio a questo soprattutto mirava: a riscoprire e a ripresentare, in un linguaggio ovviamente accessibile al largo pubblico, la sostanza dei vecchi poemi e romanzi di cavalleria, ridotti alle dimensioni di graziose «miniatures», come allora si diceva. Accanto a questi «riassunti» $o$ a queste rielaborazioni di opere più o meno antiche, La Bibliothèque pubblicava però anche testi contemporanei, composti tuttavia sulla falsariga di quelli che erano stati composti originariamente nei secoli passati. Furono molti gli scrittori, più $\mathrm{o}$ meno noti, che si prestarono a queste operazioni: attratti un po' dal facile 
guadagno, un po' dalla moda allora imperante, un po' dal gusto per la mistificazione che questo gioco comportava. Anche a Madame Riccoboni fu chiesto di collaborare, e la scrittrice che, sul declinar della vita era forse ormai stanca di scrivere l'ennesima storia d'amore infelice, accettò con entusiasmo la proposta, e nel giro di poco più di un anno compose quattro Histoires, che furono pubblicate tra il 1779 ed il 1780. Di queste una è stata ristampata da Henri Coulet nel volume Nouvelles du XVIII siècle da lui curato, qualche anno fa, per la Pléiade, le altre tre sono riproposte in questo volumetto. La prima, la più lunga, è intitolata Histoire des amours de Gertrude, dame de Château-brillant, et de Roger, comte de Montfort, la seconda, la più breve, Histoire d'Aloïs de Livarot, la terza Aventures de la Germanie. Histoire de Christine de Souabe et de Sigefried, comte de Surger. I titoli, di per sé, sono abbastanza significativi; tuttavia a parte nella prima, la colorazione troubadour è ridotta al minimo: anche per quanto riguarda l'epoca, l'autrice preferisce situare le sue Histoires tra Cinque e Seicento, in un'epoca cioè la quale più che al Medioevo ed ai romanzi di cavalleria, rinvia al tempo ed al clima del romanzo pastorale, al quale in effetti si ispira come faranno negli anni successivi altri scrittori, anche più noti, come Bernardin de Saint Pierre e Florian. Di modo che la partecipazione di Mme Riccoboni alla Bibliothèque Universelle des Romans, oltre che quantitativamente modesta, risulta anche un po' marginale. Come la stessa Madame Riccoboni ebbe a dire al suo amico Robert Liston, la sua partecipazione alla Bibliothèque fu per lei sopratutto una distrazione, un gioco al quale partecipò di buon grado, ma senza impegnarsi troppo, con dei testi abbastanza gradevoli alla lettura, ma un po' mièvres e che comunque non aggiungono, a nostro avviso, nulla ai meriti della scrittrice, da ricercare decisamente altrove. 